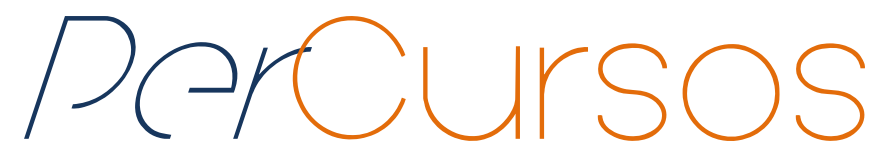

\title{
Jovens infratores em Araguaína/TO e sociedade de consumo
}

\begin{abstract}
Resumo
Os padrões impostos pela sociedade de consumo alteraram o modo das pessoas se relacionarem, a forma como se identificam socialmente e os seus valores, tendendo a formar uma massa homogênea de consumidores com reduzida capacidade crítica. A soma da necessidade de adquirir símbolos de status quo e de produtos legitimados pela ideia de pertencimento social configuram-se como essenciais na construção de identidade. Observamos que muitas das infrações cometidas por jovens estão circunstanciadas pela busca de obtenção de determinados objetos de legitimação social. O objetivo geral deste trabalho foi identificar, por meio de análise documental, o tipo de ato infracional cometido pelos adolescentes em cumprimento de Prestação de Serviço à Comunidade e Liberdade Assistida no Brasil e, mais especificamente, no município de Araguaína-TO, bem como a correlação entre o tipo de infração praticado e a dinâmica de consumo das sociedades contemporâneas, tendo como fundamento a teoria proposta por Bauman. A metodologia adotada fundamentou-se no levantamento de dados oficiais encontrados nos censos do governo federal e nos processos judiciais do Centro de Referência Especializado em Atendimento ao Indivíduo e a Família de Araguaína-TO, referentes ao mês de agosto de 2018. Esse procedimento permitiu refletir sobre a fragilidade dos jovens infratores frente à contemporaneidade, bem como a necessidade da elaboração de políticas públicas minimizadoras de desigualdades.
\end{abstract}

Palavras-chave: Jovens infratores. Medidas socioeducativas. Sociedade de consumo. Araguaína (TO).

\author{
Miguel Pacífico Filho \\ Doutor e Mestre em História pela \\ Universidade Estadual Paulista - \\ UNESP/Assis. Professor da \\ Universidade Federal do \\ Tocantins - UFT/Araguaína. \\ Brasil \\ miguilim@uft.edu.br
}

\section{Thelma Pontes Borges}

Doutora em Psicologia Escolar e do Desenvolvimento Humano pela Universidade de São Paulo USP. Professora da Universidade

Federal do Tocantins UFT/Araguaína. Brasil

thelmapontes@uft.edu.br

Laísa Lopes Ribeiro
Mestranda em Demandas
Populares e Dinâmicas Regionais
na Universidade Federal do
TocantinsUFT/Araguaína.
Brasil
laisalr@hotmail.com

Laísa Lopes Ribeiro pulares e Dinâmicas Regionais na Universidade Federal do Brasil

\section{Para citar este artigo:}

PACÍFICO FILHO, Miguel; BORGES, Thelma Pontes; RIBEIRO, Laísa Lopes. Jovens infratores em Araguaína/TO e sociedade de consumo. Revista PerCursos, Florianópolis, v. 20, n.44, p. 258 - 279, set./dez. 2019.

\section{DOI: $10.5965 / 1984724620442019258$}

http://dx.doi.org/10.5965/1984724620442019258 


\title{
Young infringers in Araguaína/TO and consumer society
}

\begin{abstract}
The patterns of ownership of social change have altered the way they relate, how they socially identify themselves, and their values, forming a homogeneous mass of consumers with critical capacity. Impossibility to acquire status quo symbols through communication channels, and these are legitimated by the idea of social belonging and identity building. Observations about infrastructures with the participation of young women are conditioned to find objects of social legitimation. The type of work was developed through a series of documentary evaluations and the type of infraction committed by the adolescents in accordance with the Community Service Provision and the Freedom of Care in the municipality of Araguaína-TO. contemporary, based on class classes and resources fed by Bauman in the book Life for Consumption. The methodology adopted is not hierarchical in the judicial processes of the Reference Center Specialized in Assistance to the Individual and Family of Araguaína-TO, referring to the period of August. This procedure included the fragility of young offenders against contemporaneity, as well as the formulation of public policies that minimize inequalities.
\end{abstract}

Keywords: Young infringers. Educational measures. Consumer society. Araguaína (Tocantins, Brazil). 


\section{Introdução}

A percepção da vida na contemporaneidade volta-se para a discussão das mudanças de comportamento social a partir de relações de consumo e da fragilidade dos laços sociais. O aumento da troca de informações e a facilidade de comunicação produziu um efeito adverso, em que as pessoas trocam relações reais por virtuais e, imersas num mundo da fugacidade, são levadas a entender que tudo pode ser comercializado e substituído. Bauman $(2005,2008)$ apresenta tal discussão demonstrando o quão volúvel e fragmentada a sociedade está e como se submete à compra incessante de produtos, alimentando padrões insustentáveis de consumo. Para o autor, a máquina econômica gira em função da ordem instituída, na qual a metáfora da água é perfeita: a contemporaneidade ou modernidade líquida é caracterizada por não ter forma ou por se modificar o tempo todo. Assim, as relações afetivas, os produtos, os comportamentos são fluidos e se destacam pelo contraponto ao sólido e à segurança de determinadas configurações de relacionamentos sociais.

Na modernidade líquida trocou-se a segurança das instituições - família, Estado, emprego - pela liberdade individual, produzindo caminhos pouco previsíveis e solidão intensa. $O$ individualismo é característico, juntamente com as tentativas de sua superação pelas vias da medicalização, como o uso de antidepressivos, ou a busca por atividades cada vez mais radicais e únicas, entre outras (LA TAILLE, 2009).

As alterações geradas pela modernidade líquida fizeram com que a era da sociedade da produção se convertesse na do consumo. Assim, a identidade, na atualidade, se firma justamente no consumir que, por tal atributo, torna-se muito mais do que apenas aquisição de produtos: revela uma personalidade. É naturalmente o "ter" o definidor do “ser”. E para consumir é necessário descartar, tornando tudo efêmero (BAUMAN, 2008). Nesta lógica, Bauman (2008) apresenta que o bem-estar social está diretamente relacionado à capacidade de consumir e de demonstrar poder por tal via.

A afirmação social em torno do consumo está presente na vida dos jovens ${ }^{1}$ que cumprem medidas socioeducativas de Liberdade Assistida e Prestação de Serviço à

\footnotetext{
${ }^{1}$ Os termos jovem, menor e adolescente são utilizados como sinônimos neste trabalho. Compreende-se o jovem como aquele que tem entre 12 e 18 anos incompletos (BRASIL, 1990).
} 
Comunidade, tanto no Brasil, de forma geral, quanto no Tocantins e, especificamente, no município de Araguaína-TO. Este artigo objetiva analisar as características e os tipos de atos infracionais cometidos pelos adolescentes em cumprimento dessas duas medidas, por meio de documentos oficiais do governo federal dos últimos anos e, em Araguaína, pela análise dos processos judiciais disponíveis no Centro de Referência Especializado de Assistência Social (CREAS), que compreendeu o período de agosto de 2018.

Como resultado, para Araguaína, 78,4\% e, para o Brasil, 53\% dos atos infracionais são de cunho patrimonial, dado que indica poder haver influência da cultura do consumo entre os jovens. Cabe ressaltar que a suposição da cultura de consumo não desconsidera fatores intervenientes, como complicações no desenvolvimento da adolescência, desigualdades sociais e dificuldades de acesso a bens e serviços etc. Compreender o elemento da sociedade de consumo e sua interferência na conjuntura social é de extrema importância para a vida em sociedade e para se pensar em políticas de intervenção e processos educativos que assimilem a cultura de consumo como fator de relevância.

Optou-se por análise documental de dados secundários produzidos pelos governos federal e municipal ${ }^{2}$ sobre a infância e adolescência no Brasil, a fim de demonstração da tese deste artigo, a saber, que, sendo os atos infracionais das crianças e adolescentes tanto no Brasil quanto em Araguaína/TO, em sua maioria, de ordem patrimonial, induzem a pensar que a internalização do consumismo como afirmação da identidade, a liquidez das relações, a solidão, a efemeridade do tempo, entre outros problemas debatidos por Bauman (2008), atingem essa população.

A escolha dos documentos foi feita a partir de uma longa análise dos fenômenos por parte dos pesquisadores, permitindo o foco do olhar naquilo que auxilia a demonstrar o problema, selecionando informações e correlacionando com os aspectos analíticos e teóricos propostos (MINAYO, 2008). Entre os documentos consultados para situar o Brasil estão o "Cenário para a Infância e Adolescência no Brasil -2019" (FUNDAÇÃO ABRINQ, 2019) e o "Levantamento Anual SINASE-2016" (BRASIL/SINASE, 2018). Para

\footnotetext{
${ }^{2}$ Ressalta-se não ser possível trabalhar com as informações do Tocantins, uma vez que os dados não estão disponíveis.
} 
Araguaína/TO foi realizada uma análise documental dos dados constantes nos processos judiciais pertencentes à demanda do CREAS, com o intuito de verificar quais os atos infracionais mais recorrentes entre os adolescentes. A análise compreende somente aqueles adolescentes que estavam cumprindo medidas socioeducativas de Liberdade Assistida e/ou de Prestação de Serviço à Comunidade.

Foram retirados dos documentos dados que permitissem verificar as condições de vida das crianças e adolescentes brasileiros e, na região norte do Brasil, onde fica situada a cidade de Araguaína/TO, bem como informações sobre o tipo de infração cometido por essa população.

O trabalho foi dividido em três tópicos: o primeiro se refere às discussões propostas por Bauman $(2005,2008)$ sobre a necessidade do jovem em consumir e a obediência profunda às leis do consumo como meio de adquirir identidade social. $O$ segundo tópico explana sobre o que são as medidas socioeducativas nas modalidades Prestação de Serviço à Comunidade e Liberdade Assistida, e discute os resultados da pesquisa de análise documental. Posteriormente são apresentadas as conclusões, a partir da análise das discussões propostas de modo geral.

\section{Contemporaneidade, sociedade de consumo e adolescência}

Na contemporaneidade é possível afirmar que os parâmetros sociais são definidos pela ótica capitalista, gerando uma cultura consumista supostamente produtora de identidades, elevando o consumismo a um ato vocacional, conforme descreve Bauman (2008, p. 73): "numa sociedade de consumidores, todo mundo precisa ser, deve ser e tem que ser um consumidor por vocação (ou seja, ver e tratar o consumo como vocação)". Essa cultura é definida por La Taille como um "achatamento de valores" (2009, p. 41): “Logo, o achatamento de valores não apenas acarretaria sérios prejuízos para a eleição de planos de vida, mas também a construção da própria identidade" (LA TAILLE, 2009, p. 47).

De acordo com essa dinâmica, as pessoas reconhecem umas às outras por meio de marcas e objetos, e isso é o que irá determinar a sua singularidade e inserção social. 
Acertadamente, Birman (1998) reflete sobre esse sistema afirmando que a hegemonia da aparência é o que define o ser, em que é atribuído valor àquilo que parece ser; para isso há uma estetização do eu e, a todo tempo, os indivíduos buscam evidenciar-se por meio de bens materiais. Características como o culto à aparência, o consumo, o parecer antes de ser, são definidoras do que Bauman (2005) denominou como contemporaneidade ou mais precisamente como sociedade líquida.

Essa cultura consumista e desigual atinge severamente a formação dos adolescentes, formando um exército de consumidores engajados. Os jovens se veem atraídos pelo desejo de serem vistos e reconhecidos socialmente como pessoas de valor, que se sobressaem aos outros, pois, assim como os demais, vivem num tempo em que aquilo que tem valor é o que representa o acesso à riqueza monetária.

A vulnerabilidade típica da contemporaneidade provoca alterações, fazendo com que os valores sejam líquidos e efêmeros. Nesse sentido, a identidade também se estrutura sobre areia movediça, podendo bailar para qualquer lado. É então fácil compreender que a contemporaneidade impõe significativos parâmetros aos adolescentes, que por definição estão tentando encontrar sua estruturação psicológica, contudo conseguem apenas captar o jogo do movimento, indo e vindo de uma relação à outra, consumindo não somente produtos manufaturados, como relações socioafetivas (BAUMAN, 2005).

É, pois, durante a adolescência que a tarefa de construção da identidade adquire maior relevo. A necessidade de se descobrir a si próprio, por oposição ou identificação com o meio familiar e com o grupo de amigos ou colegas da escola, provoca no adolescente situações de conflito em que a tomada de decisões se torna mais ou menos imperativa. (AMANTE et al., 2014, p. 27).

As campanhas publicitárias muitas vezes atribuem caráter essencial a objetos irrelevantes, tornando-os a materialização e a perfeita tradução da felicidade. Só que a busca pela felicidade é infinita, porque a todo tempo são lançados novos produtos e a sua felicidade se esvai junto com o produto antigo. Bauman (2008, p. 60) define que "o valor 
mais característico da sociedade de consumidores, na verdade seu valor supremo, em relação ao qual todos os outros são instados a justificar seu mérito, é uma vida feliz". Se o mercado lançou a obsolescência programada dos objetos, a sociedade lançou a obsolescência programada da felicidade. Assim, as expectativas dos adolescentes/consumidores são quebradas constantemente, pois "a taxa de mortalidade das expectativas é elevada; numa sociedade de consumo funcionando de forma adequada, ela deve estar em crescimento constante" (BAUMAN, 2008, p. 65).

A falta de significado da própria existência faz com que as pessoas busquem algo para lhes definir, uma busca sem sentido posto que insaciável, a construção de uma identidade incompleta que a todo momento precisa fazer reparos. A carência emocional e a falta de um sentido vibrante da vida, como boas relações sociais fundadas na valoração de virtudes, conduz facilmente os indivíduos à vigência da lei do mercado.

\begin{abstract}
A sociedade de consumo tem como base de suas alegações a promessa de satisfazer os desejos humanos em um grau que nenhuma sociedade do passado pôde alcançar, ou mesmo sonhar, mas a promessa de satisfação só permanece sedutora enquanto o desejo continua insatisfeito; mais importante ainda, quando o cliente não está "plenamente satisfeito" - ou seja, enquanto não se acredita que os desejos que motivaram e colocaram em movimento a busca da satisfação e estimularam experimentos consumistas tenham sido verdadeira e totalmente realizados. (BAUMAN, 2008, p. 63).
\end{abstract}

A lei do consumo é severa, não prevendo qualquer anistia ou remissão - ou você compra ou é punido. Mas punido por quem? Pela própria sociedade, que irá excluir todos os que forem indiferentes ao "culto" do consumismo. E, nessa exaltação aos produtos, não vale ser infiel, ou seja, consumir esporadicamente; é preciso uma lealdade diária, comprar sem cessar. Em uma análise mais profunda sobre a sociedade consumidora, Bauman esclarece que

As leis do mercado se aplicam, de forma equitativa, às coisas escolhidas e aos selecionadores. Só as mercadorias podem entrar nos templos de consumo por direito, seja pela entrada dos "produtos", seja pela dos 
"clientes". Dentro desses templos, tanto os objetos de adoração como seus adoradores são mercadorias. (BAUMAN, 2008, p. 82).

Afirma, ainda, que todos aqueles que estão imersos nessa sociedade são consumidores de jure:

\footnotetext{
Ser um "consumidor de jure" é, para todos os fins práticos, o "fundamento não jurídico da lei", já que precede todos os pronunciamentos legais que definem e declaram os direitos e obrigações do cidadão. (BAUMAN, 2008, p. 83).
}

Para adentrar a essa sociedade e obter um visto de residência permanente, tanto homens como mulheres devem acatar os requisitos de elegibilidade impostos, de acordo com o padrão de mercado. Desse modo, cada membro deve buscar seu "valor de mercado" em competição com o outro, visando sempre o valor mais favorável (BAUMAN, 2008, p. 82).

Esses dispositivos criados pela sociedade de consumo podem levar os jovens à evasão ou ao atraso escolar e à prática de atos infracionais, na busca de adquirirem imediatamente os símbolos capazes de determinar o seu lugar no campo social, principalmente para aqueles cuja condição social estabelece um fosso entre o desejo e a possibilidade de acessar bens de consumo. Numa sociedade desigual, imediatista e hedonista torna-se difícil a um adolescente sonhar com o longo percurso de uma formação e estabilização financeira até alçar os louros da vitória social, mesmo porque, desde cedo, ele é imerso numa estratégia de captura pelo marketing.

Tão logo aprendem a ler, ou talvez bem antes, a "dependência das compras" se estabelece nas crianças. Não há estratégias de treinamento distintas para meninos e meninas - o papel de consumidor, diferentemente do de produtor, não tem especificidade de gênero. (BAUMAN, 2008, p. 73). 
A lógica capitalista, que tanto trabalha pela instalação de uma cultura consumista, renega a boa parte da população (a que se encontra abaixo da linha da pobreza) a sua prática; mas nem por isso a cultura consumista deixa de influenciar aqueles que não podem usufruir dos bens de consumo, pela tensão provocada pelo binômio cidadaniaconsumidor. E, talvez, até por conta dessa tensão existe a possibilidade dos atos infracionais de adolescentes se configurarem como sintoma desse estresse social (ROSA, 2016).

Naturalmente, a adolescência é uma fase de transição e descoberta; o problema é quando os jovens são influenciados de modo negativo a aderirem a comportamentos e atitudes que os deixam cada vez mais distantes do ser. Na verdade, o que eles mais anseiam é serem vistos, só que não pelo ser e sim pelo simples ter; acreditam que desse modo encontrarão o seu grupo, e não se tornarão invisíveis perante os outros. E, para não desaparecerem, tudo ou quase tudo é possível: vale se expor a riscos letais, ferir o outro, fazer uma transferência de renda forçada (roubar, furtar), romper os laços familiares, mentir e enganar. Como diz La Taille (2009, p. 176), “todo mundo quer 'ser'; o vaidoso, além de querer 'ser', quer 'se destacar'." Como os valores são efêmeros e as relações sociais fragmentadas, romper com padrões de comportamento se torna mais fácil, uma vez que no custo-benefício têm-se a sensação da vitória instituída.

Na lógica da sociedade de consumo são os adolescentes, justamente, os mais vulneráveis à sedução. O deus mercado trabalha permanentemente para assimilar indivíduos que a princípio não se enquadravam nas suas normas sedutoras; como o consumo divide as pessoas em grupos opostos, Bauman (1998, p. 55) afirma que "A sedução do mercado é, simultaneamente a grande igualadora e a grande divisora”.

Desse modo, nossa sociedade é reconfigurada pelo modelo capitalista de desenvolvimento, gerando enormes diferenças sociais, caracterizadas pelo individualismo e consumismo. Os meios midiáticos criam modelos e padrões de vida, os quais são "vendidos", e a inclusão ou não nesse modelo é definida pela capacidade que cada pessoa tem para consumir. Castel (2015) classifica os excluídos desse contexto como “sobrantes”, definidos assim por não terem participação no mercado. O próprio termo sobra, em seu sentido etimológico, se refere àquilo que fica depois que o necessário é 
retirado - nesse caso, o necessário, para a sociedade de consumo, são os que possuem o poder de compra, enquanto os outros podem ser excluídos, pois são apenas "sobrantes" sem nenhum valor.

O que cabe para os adolescentes, que vivem à margem da pobreza e sem poder de compra, senão o lugar da sobra, do resto? Talvez, assumir a identidade pelo objeto que ostentam seja de fato uma saída viável ou, quem sabe, ser reconhecido como menor infrator garanta mais reconhecimento e status quo, pois não são vistos como sujeitos, mas como restos sociais. A identidade "menor infrator" é um lugar subjetivo: mesmo que seja o da contravenção, mas é um espaço de poder e atividade (ROSA, 2016).

No final do século XX, Castel (2015, p. 35) refletia sobre a forma estrutural da sociedade ocidental dessa época, afirmando que "estamos, sem dúvida, diante de uma bifurcação: aceitar uma sociedade inteiramente submetida às exigências da economia ou construir uma figura do Estado Social à altura dos novos desafios". Essa reflexão é plenamente válida hodiernamente, pois permanecemos diante dessa bifurcação.

30 jovem, o ato infracional e as medidas socioeducativas no Brasil e em Araguaína

O Estatuto da Criança e do Adolescente (ECA) prevê medidas socioeducativas (MSE) para responsabilizar de modo pedagógico o jovem que comete ato infracional ${ }^{3}$. Cumpre destacar algumas MSE definidas no art. 112 do ECA: “ I - advertência; II - obrigação de reparar o dano; III - prestação de serviços à comunidade; IV - liberdade assistida; V inserção em regime de semiliberdade; VI - internação em estabelecimento educacional; VII - qualquer uma das previstas no art. 101, I a VI" (BRASIL, 2018).

São consideradas como Medidas Socioeducativas em Meio Aberto a prestação de serviços à comunidade (PSC) e a liberdade assistida (LA). Para que o adolescente cumpra MSE em meio aberto é necessário que haja um devido processo legal, o qual impõe

\footnotetext{
${ }^{3}$ Ato infracional é aquele análogo a crime ou contravenção penal; é assim denominado por ser praticado por pessoas menores de 18 anos, as quais não serão criminalizadas ou punidas, apenas responsabilizadas de modo pedagógico.
} 
limites à atuação do Poder Judiciário, aplicando sanções somente nas hipóteses previstas em lei. Conhecer a natureza jurídica das MSE e as razões que levaram o Judiciário à execução é basilar para os profissionais que atuam na seara menorista, em especial, os responsáveis pelo cumprimento das MSE de LA e PSC, pois a ciência do ato infracional praticado ajuda na avaliação da MSE aplicada, analisando se ela é proporcional ou não.

A Prestação de Serviço à Comunidade (PSC) respeita a jornada máxima de oito horas semanais, podendo ser exercida aos finais de semana, feriados e dias úteis, desde que não atrapalhe a jornada escolar do adolescente e não ultrapasse o período de seis meses. A Liberdade Assistida caracteriza-se por acompanhar o adolescente de modo sistemático, incluindo o desempenho escolar. Por não ser objetivo deste trabalho, não serão abordadas as metodologias utilizadas na aplicação das MSE e as formas de articulação com possíveis parceiros ${ }^{4}$.

De acordo com o levantamento anual do Sistema Nacional de Atendimento Socioeducativo (BRASIL, 2018), no ano de 2016 existiam 25.929 adolescentes/jovens cumprindo medidas de restrição de liberdade e 521 em outras modalidades de atendimento, totalizando 26.450 jovens no sistema nacional, de uma população de 26 milhões de pessoas entre zero e dezenove anos (FUNDAÇÃO ABRINQ, 2019). Desse total, $70 \%$ cumpria medida de internação, 20\% internação provisória e $8 \%$ semiliberdade. Em termos de distribuição por região, a maioria dos jovens encontrava-se no Sudeste, com $57 \%$, seguida pelo Nordeste, com $20 \%$. Na região Norte, eram $6 \%$ do total. O Tocantins se enquadrava entre os seis estados brasileiros com menos de 200 jovens internados.

Dos 27.799 atos infracionais cometidos em 2016, apenas 3,38\% foram realizados por meninas/mulheres (total de 942 infrações). Com relação à restrição de liberdade, 96\% (25.360) são de jovens do sexo masculino e 4\% (1.090) do sexo feminino, demonstrando que o sexo masculino está mais vulnerável e predisposto a ações ilícitas do que o sexo

\footnotetext{
${ }^{4}$ Para compreensão do assunto ver: MINISTÉRIO DO DESENVOLVIMENTO SOCIAL. Caderno de orientações técnicas: serviços de medidas socioeducativas em meio aberto. Brasília: Secretaria Nacional de Assistência Social, 2016. Disponível em: https:/www.google.com/url?sa=t\&rct=j\&q=\&esrc=s\&source= web\&cd=5\&ved=2ahUKEwi6uOGPqqnmAhUZG7kGHceDAEQQFjAEegQIBBAC\&url=https\%3A\%2F\%2Fwww. mds.gov.br\%2Fwebarquivos\%2Fpublicacao\%2Fassistencia_social\%2FCadernos\%2Fcaderno_MSE_0712.pdf\&u sg=AOvVaw2IPAUJ_G4eF4M3cmzc8Ctl . Acesso em: 09 dez.2019.
} 
feminino. Há a necessidade de novas pesquisas que consigam elucidar o porquê dessa diferença de gênero, mas algumas hipóteses se fazem presentes, entre elas: a menina ser mais controlada e vigiada pela família, socialmente não cabe à mulher conquistar os objetos de consumo, aos meninos a independência é exigida mais cedo etc. Outro dado relevante é que 59,08\% dos jovens em privação de liberdade são identificados como negros/pardos, 22,49\% brancos, 0,98 indígenas, 0,91 amarelos e 16,54\% sem informação, demonstrando que a incidência penal sobre a população negra é significativamente maior desde a adolescência, coadunando com os dados deste mesmo perfil populacional nos presídios (BRASIL, 2018). A maior proporção de negros em atos infracionais e nos presídios pode ser representativa das sementes da escravidão na sociabilidade brasileira (SOUZA, 2017). Para Souza (2017), o Brasil não superou suas raízes escravocratas e as reatualiza nas relações sociais, garantindo que tudo permaneça como está e estabeleça que na sociedade existam cidadãos de segunda categoria, como os negros.

Do ponto de vista da infração, verifica-se, no gráfico a seguir, que entre roubo (47\%), furto (3\%), latrocínio (1\%), tentativa de roubo e receptação (ambos com 1\%), 53\% dos atos cometidos pelos jovens infratores têm relação direta com a aquisição (ou tentativa) de objetos de consumo.

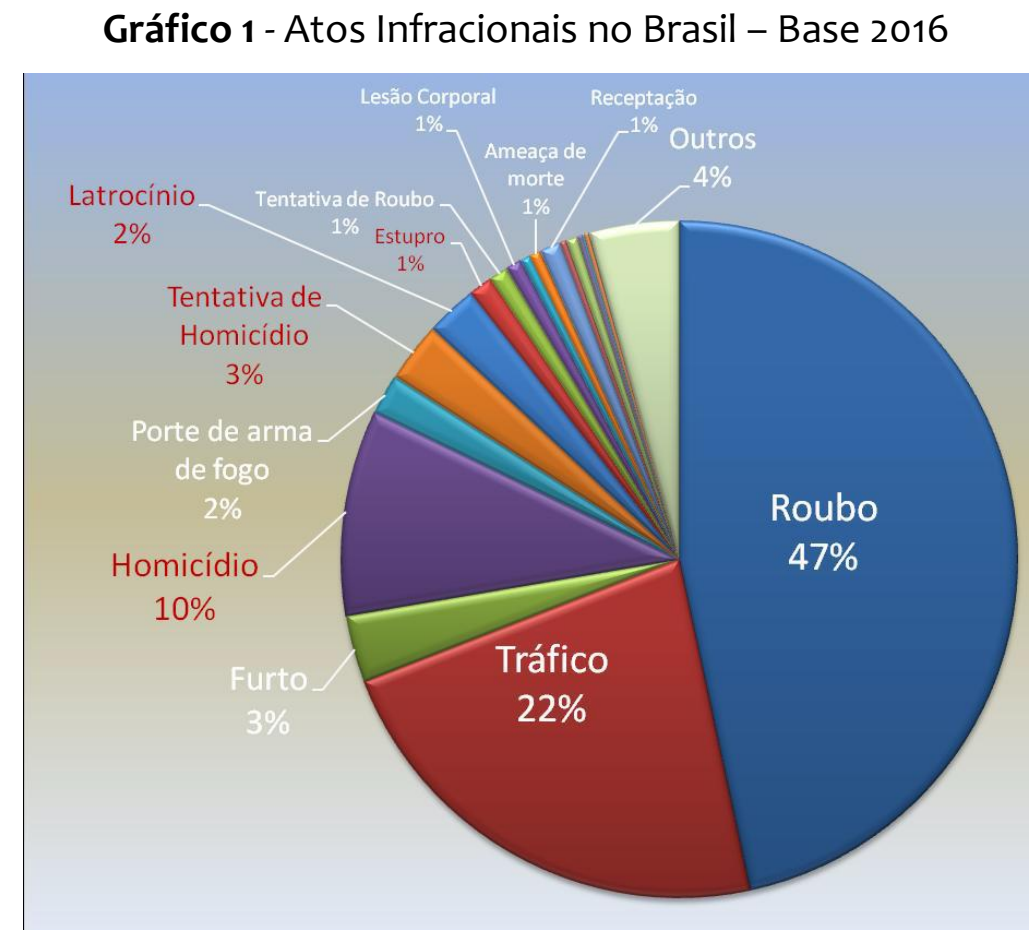

Fonte: SINASE, 2018. 
Nos dados de 2011, obtidos do Ministério da Justiça, as infrações patronais envolvendo furtos e roubos eram da ordem de 43,7\% (MAGALHÃES, 2015), demonstrando um aumento nesta tipagem entre 2011 e 2016.

Ao considerar que, em 2018, dos 68 milhões de crianças e adolescentes no Brasil, 63,5 milhões vivem em situação de pobreza e, desses, 26,8 milhões em situação de extrema pobreza (FUNDAÇÃO ABRINQ, 2019), pode-se considerar que o total de infrações é baixo e a tentativa de reversão do problema da pobreza via atos ilícitos de roubo e furto também.

Com a integração do Sistema Único de Assistência Social ao ordenamento jurídico brasileiro, em 2011, foi instaurada a proteção social básica, desenvolvida pelo Centro de Referência de Assistência Social (CRAS), e a proteção social especial, ofertada pelo Centro de Referência Especializado de Assistência Social (CREAS). Funcionam no Município de Araguaína/TO esses dois órgãos, vinculados à Secretaria de Assistência Social, Trabalho e Habitação, possibilitando verificar se essa tipagem de ato infracional se repete nessa cidade.

A vulnerabilidade existente em Araguaína, conhecida como "Capital Econômica" do Estado do Tocantins, é observada pela desigualdade na distribuição de renda. De acordo com a SEPLAN-TO (2017), com base na tabela do PNUD sobre porcentagem da renda apropriada por estratos da população em Araguaína, no ano de 2010 20\% dos mais ricos detinham $61,24 \%$ da renda gerada na cidade, frente a $80 \%$ dos mais pobres, que detinham 38,76\%. Esses dados aclaram as diferenças sociais existentes, e pressupõem uma série de problemas decorrentes dessas disparidades econômicas, inclusive a crescente criminalidade entre os jovens.

Guimarães (2015) aponta que um dos fatores que predispõem ao ato infracional os jovens é a desigualdade econômica, em um país que se constituiu historicamente a partir da segregação econômica e racial. Assim, imagina-se que, se mais de sessenta por cento da renda de Araguaína concentra-se nas mãos de apenas vinte por cento da população, a cidade, assim como o Brasil, tem o elemento econômico como fator intensificador de 
problemas sociais. Os demais agentes citados pelo autor como correlacionados ao ato infracional são a evasão escolar ou o baixo rendimento, a utilização de drogas e a questão racial.

Em agosto de 2018, dos 51 (cinquenta e um) adolescentes em cumprimento de medidas socioeducativas em Araguaína, 28 (vinte e oito) socioeducandos cometeram ato infracional análogo ao crime de roubo (art. 157 do CPB), 8 (oito) praticaram furto, 4 (quatro) receptação; só esses crimes contra o patrimônio com interesse de obter benefício próprio contabilizam 40 (quarenta). Ou seja, 78,4\% dos atos cometidos pelos adolescentes, no município supracitado, são de cunho patrimonial. Esse valor pode simbolizar muitas possibilidades: os anseios e as necessidades desses jovens de se enquadrarem na sociedade de consumo, de superarem suas dificuldades sociais e econômicas, de participarem da sociedade, de se afirmarem como seres humanos, de conseguirem recursos financeiros para suprir necessidades básicas e/ou comprar remédios, entre outros. A sociedade de consumo é mais um fator a ser relatado quando das leituras possíveis do ato.

Tabela 1 - Crimes cometidos por adolescentes em cumprimento de medidas socioeducativas em agosto de 2018 - Araguaína/TO

\begin{tabular}{|l|c|l|}
\hline Ato infracional análogo ao tipo penal & Quantidade & Idade $^{5}$ \\
\hline Roubo & 28 & $15,16,17,18,19$ anos \\
\hline Furto & 8 & $14,15,17,18$ anos \\
\hline Receptação & 4 & $13,16,17,18$ anos \\
\hline Posse de droga para consumo & 4 & 16,17 anos \\
\hline Ameaça & 2 & 17,18 anos \\
\hline $\begin{array}{l}\text { Infração contra o sistema financeiro } \\
\text { nacional }\end{array}$ & 1 & 18 anos \\
\hline Associação para o tráfico & 1 & 17 anos \\
\hline
\end{tabular}

\footnotetext{
${ }^{5} \mathrm{~A}$ idade não corresponde ao momento da prática do ato infracional, e sim à idade que possuíam no mês analisado.
} 


\begin{tabular}{|l|c|l|}
\hline Desacato & 1 & 18 anos \\
\hline Homicídio simples & 1 & 15 anos \\
\hline Incêndio & 1 & 21 anos \\
\hline Infração de trânsito & 1 & 19 anos \\
\hline Lesão corporal & 1 & 17 anos \\
\hline Tráfico de drogas & 1 & 18 anos \\
\hline
\end{tabular}

Fonte: Dados coletados e sistematizados pelos autores a partir dos processos judiciais.

Quanto ao perfil dos 51 (cinquenta e um) adolescentes, 3 (três) são do sexo feminino e cometeram os seguintes atos infracionais: ameaça, lesão corporal, porte de droga para consumo pessoal e homicídio. Os dados específicos de Araguaína repetem a baixa incidência de menores do sexo feminino nos atos infracionais. Guimarães (2015) considera que os atos com relação ao tráfico de drogas também podem estar correlacionados à aquisição rápida de dinheiro e status social, com a finalidade de obter insumos da sociedade de consumo. No caso de Araguaína, temos 6 (seis) casos do tipo, que somados aos 40 (quarenta) anteriores, representam quase a totalidade dos atos infracionais. Nos dados apresentados no gráfico 1, 22\% dos atos são por tráfico de drogas.

Consumir, de acordo com os parâmetros estabelecidos pela contemporaneidade, é uma forma de ser visto, de deixar a invisibilidade; consumir é pertencer à sociedade. Outro dado importante relacionado aos adolescentes de Araguaína é que, a partir dos endereços indicados nos processos que foram analisados, esses adolescentes residem em setores carentes da cidade, setores esquecidos pelo poder público e pela sociedade, podendo-se ter como hipótese que o ato infracional pode provocar a sensação de visibilidade. Eles não querem ser esquecidos, precisam ser vistos em algum momento, sentem a necessidade de dizer "eu estou aqui' e o modo mais fácil de dizer isso é consumindo e/ou agredindo.

A sociedade de consumo está posta como uma das características da contemporaneidade, seduzindo as pessoas e principalmente os mais jovens. Tal fato deve ser considerado quando se observam as dinâmicas de comportamentos individuais. Nos mais de 50 (cinquenta) crimes previstos no Código Penal Brasileiro, os adolescentes de 
Araguaína cometem recorrentemente apenas três tipos - roubo, furto e receptação, que somados equivalem a $78,4 \%$ do total de atos infracionais praticados no município. Essa porcentagem expressiva permite trabalhar, como hipótese, para além daquelas já relatadas, as tentativas feitas pelo público juvenil de não serem rotulados como pessoas impotentes frente ao consumo, acessando bens como os demais. Pode-se supor, ainda, que sejam uma tentativa de amenizar a realidade precária em que vivem, criando outra realidade definida pelo poder de compra. Vale ressaltar que os adolescentes que cometem infrações mais graves ou que são reincidentes podem receber outras medidas socioeducativas (como exemplo, internação até três meses ou semiliberdade); progredindo de regime, passam a cumprir PSC e LA, por esse motivo temos na tabela o crime de homicídio.

Um dos requisitos para cumprir a medida socioeducativa de Liberdade Assistida é que o jovem deve estar matriculado na escola, obtendo notas razoáveis e comparecendo às aulas regulamente. A equipe multidisciplinar (psicólogo, assistente social, pedagogo e advogado) do CREAS de atendimento aos socioeducandos acompanha essa trajetória, e sempre que preciso se reúne com o jovem, visando fazer com que ele reflita sobre os seus atos de modo positivo e que adote uma nova postura, benéfica à sua vida e a de seus pares.

A inserção social advinda da educação ocorre no médio e longo prazo, por isso, outra hipótese que se coloca é: quando os jovens olham todo o percurso que precisam realizar para satisfazer as suas vontades consumistas, há desestímulo, em decorrência do imperativo do agora, um dos pilares da contemporaneidade. La Taille (2009) compreende que a vida do homem moderno é regida por uma espécie de ditadura da velocidade, denominando esse fenômeno de "tacocracia". A tacocracia é definida pela velocidade/rapidez em que as coisas precisam ser realizadas e a valoração que é atribuída a elas; assim, não há certeza de valores, pois amanhã tudo pode ser ressignificado de modo a beneficiar o consumo (LA TAILLE, 2009). Nos documentos analisados, todos os jovens estão fora da idade escolar adequada à série que estão cursando, ou seja, estão “atrasados". Como apresentado por Safi, na visão dos jovens infratores, a educação nem sempre foi um dos caminhos disponíveis, eles 
precisam consumir para serem reconhecidos socialmente, mas devem fazer isso através das limitadas possibilidades em que vivem, e ainda sem conseguir vislumbrar muitas alternativas futuras de trabalho em relação aos outros jovens de classes mais abastadas. Muitos desses jovens acabam por cometer atos infracionais pela possibilidade de também poderem consumir os objetos de pretensa felicidade que lhes garantem um lugar na sociedade e lhes dão autonomia. (SAFI, 2013, p. 24)

Nos dados apresentados no documento "Cenário da Infância e Adolescência no Brasil" (FUNDAÇÃO ABRINQ, 2019) sobre a região norte do país, localidade em que se encontra Araguaína, a distorção série-idade no ensino fundamental é de $26,4 \%$ e no ensino médio é de 41,4\%; o abandono escolar no ensino fundamental é de $2,9 \%$ e no ensino médio de $9,8 \%$, demonstrando a fragilidade, no que tange ao sucesso escolar, dos jovens nesta região do país. Somam-se a isso as condições precárias de vida, como, por exemplo, 42,5\% dos menores no norte não têm acesso a água tratada, 75,2\% vivem em locais sem coleta de esgoto; além disso, a região norte tem uma das maiores taxas de internação hospitalar de crianças, provocada por doenças relacionadas à falta de saneamento, sendo que a taxa é de 324,8 internações para cada cem mil habitantes (comparativamente, a taxa do Brasil é de 166,8 e da região sudeste é de 75,8$)$. Tais dados demonstram que os jovens brasileiros e especificamente os do norte do Brasil encontram-se em situação de vulnerabilidade envolvendo saúde, educação e condições socioeconômicas. Além disso, vivenciam todas as mazelas produzidas pela sociedade moderna, com suas características de liquidez e consumo: o bem-estar social é definido então pelo acúmulo de bens materiais.

Bauman (2008) considera que o capitalismo é um divisor social tendo em vista a maior capacidade de consumo em determinadas localidades das cidades, o que separa bairros nobres de bairros periféricos. Como a maioria dos adolescentes de Araguaína residem nos bairros estigmatizados, de acordo com o endereço que consta no Processo Individual de Atendimento do CREAS, querem a todo custo se livrar daquilo que lhes identifica como pobres e aderir àquilo que remete à vida dos ricos, e para isso é preciso demonstrar capacidade de consumo. 


\section{Considerações finais}

No decorrer deste trabalho, buscou-se elucidar o atual modelo de sociedade caracterizada pelo consumismo, demonstrando uma flexibilização dos valores morais e éticos e, consequentemente, das relações sociais. E esse modelo - mercadológico, individualista, estético - pressiona o jovem e todos da sociedade a segui-lo e a se adequar a ele. Somam-se a essas características sociais a intensa desigualdade no Brasil, especificamente no Norte, marcada pela falta de acesso adequado à água, esgoto, educação, renda e saúde; esse contexto perverso é propício à busca de alternativas de sobrevivência, como, por exemplo, os atos infracionais.

Foi possível hipotetizar leituras dessa tentativa de enquadramento dos jovens à sociedade consumista a partir dos tipos de atos infracionais cometidos pelos adolescentes, da verificação de dificuldades de acompanhamento escolar e a raça, demonstrando aquilo que Guimarães (2015) aponta como fatores que predispõem o jovem ao crime.

A falta de amparo político e social faz com que os jovens tenham como alternativa de satisfação o consumo, para ocupar, a todo e qualquer custo, o seu espaço e formar sua identidade, buscando aumentar o seu valor sígnico ou, em outra vertente de conjecturas, para adquirir dinheiro para sanar dificuldades com alimentação, moradia ou saúde. Corrobora esse pensamento a reflexão de Bauman e Donskis (2014, p. 28): “Na sociedade de consumidores, todos nós somos consumidores de mercadorias, e estas são destinadas ao consumo; uma vez que somos mercadorias, nos vemos obrigados a criar uma demanda de nós mesmos".

Em uma sociedade na qual as relações são construídas por meio da compra desenfreada de produtos, a demanda de nós mesmos é formada pelo que adquirimos: é preciso consumir para ter valor, caso contrário somos excluídos do mercado. Nesse caso, o ato infracional se encaixa nessa demanda, em que os jovens carentes encontram a oportunidade de participar, ainda que minimamente e de forma transitória, da sedutora e quase irresistível sociedade consumista. Pelos dados apresentados, é possível inferir que as condições de vida, de uma forma em geral, não trarão maiores ganhos sociais e, 
recorrer a ações que, pelo menos momentaneamente, diminuem a sensação de nada ser ou pertencer, acaba por se configurar como minimamente interessante.

Cabe indicar que, com os dados apresentados com relação à pobreza e à falta de acesso a saneamento e saúde básica, é perverso discutir a criminalização da infância e adolescência e o aumento do recrudescimento da punição, gerando o que Cunha (2016) chamou de transformação do Estado de bem-estar social para Estado penal, em que a pobreza e a exclusão social são colaboradoras do encarceramento em massa. Há que se debater, ainda, que parte da política de criminalizar a pobreza é tida como caminho para a segurança nacional, marcando aquilo que já é estrutural no Brasil, ou seja, o lugar ocupado por jovens pobres e em sua maioria negros.

Ressalta-se que o aumento da criminalidade entre os jovens deve ser lido como resultado de transformação de uma sociedade em que o papel do Estado diminui cada vez mais, produzindo sensações de insegurança e de falta de pertencimento social. Bauman (2009) bem ressalta que a violência é resultado intangível de uma sociedade consumista, que desperta no outro a sensação de dignidade pela via da obtenção de bens de consumo. Por outro lado, é importante esclarecer que, segundo Teixeira e Salla (2016), existe uma participação reduzida de infrações de adolescentes na vida urbana, e também uma reduzida taxa de crimes violentos, como podemos verificar nos dados apontados.

Se, por um lado, se aguça o desejo pelo consumo, por outro, a grande massa da população perde a capacidade de consumir pela diminuição crescente dos postos de trabalho, alterando o status de "exército de reserva de trabalho" para o de "população redundante" (BAUMAN, 1998) ou de "sobrantes" (CASTEL, 2015). Como as massas já não possuem mais serventia, resta-lhes o ódio, tão bem demonstrado nos casos televisivos de imigrações, e na desestruturação do Estado de bem-estar social, com a flexibilização de leis trabalhistas, previdenciárias, diminuição de acesso à saúde e à educação.

De modo geral, a desestruturação de políticas sociais e a adoção do pensamento neoliberal faz crer na necessidade de um aumento do Estado policial para controle dos pobres. Assim, há a tendência cada vez maior de se discutir a redução da maioridade penal como solução para os males da violência, deixando escondido que o ato infracional 
é resultado de uma violência histórica, estrutural, de um país que se assentou nas regalias de uma minoria elitista que tem seu berço na colônia.

Para terminar, mais uma referência a Bauman (2008, p. 76), que escreveu: “É, em última instância, por essa razão que passar no teste do consumidor é condição inegociável para a admissão na sociedade que foi remodelada à semelhança do mercado". Portanto, as demandas da sociedade de consumo são algo que envolve a juventude e isso deve ser considerado como viés das políticas públicas através de processos educacionais que resgatem valores éticos e contribuam para a constituição do ser humano - como escreve La Taille (2009, p. 223), de uma "cultura do respeito de si" e que valorize o bem comum como condição. Não menos importante, uma sociedade que compreenda que as desigualdades sociais e as mazelas que assolam quase toda a infância e a adolescência brasileiras devem ser equacionadas.

\section{Referências}

FUNDAÇÃO ABRINQ. Cenário da infância e adolescência no Brasil - 2019. São Paulo: Fundação Abrinq, 2019.

AMANTE, Lúcia et al. Jovens e processo de construção de identidade na rede: o caso do Facebook. Educação, Formação e Tecnologias, Braga, v. 7, n. 2, p. 26-38, dez. 2014. Disponível em: http://www.eft.educom.pt/index.php/eft/article/view/ 414/202. Acesso em: 01 nov. 2018.

BAUMAN, Zygmunt. O mal-estar da pós-modernidade. Rio de Janeiro: Jorge Zahar Editor, 1998.

BAUMAN, Zigmunt. Vida para consumo: a transformação das pessoas em mercadoria. Rio de Janeiro: Zahar Ed., 2008.

BAUMAN, Zigmunt. Identidade. Rio de Janeiro: Zahar, 2005.

BAUMAN, Zygmunt; DONSKIS, Leônidas. Cegueira moral: a perda da sensibilidade na modernidade líquida. Rio de Janeiro: Zahar, 2014.

BRASIL. Estatuto da Criança e do Adolescente. Lei n. 8.069, de 13 de julho de 1990. Brasília, DF: Presidência da República, [1990]. Disponível em:

http://www.planalto.gov.br/ccivil_03/leis/L8069.htm. Acesso em: 15 ago. 2018. 
BRASIL. Coordenação Geral do Sistema Nacional de Atendimento Socioeducativo SINASE. Levantamento Anual SINASE 2016. Brasília, DF: Ministério dos Direitos Humanos, 2018.

BIRMAN, joel. O mal estar na modernidade e a psicanálise: a psicanálise à prova social. Physis: Revista de Saúde Coletiva, Rio de Janeiro, v.8, n. 1, p. 123-144, 1998. Disponível em: http://www.scielo.br/pdf/physis/v8n1/07.pdf . Acesso em: 09 dez. 2019.

CASTEL, Robert. As metamorfoses da questão social: uma crônica do salário. Rio de Janeiro: Vozes, 2015.

CUNHA, Raphael Leonel Santos. O menor infrator, a questão da maioridade penal e as medidas socioeducativas em prática no Brasil e no Amazonas. 2016. Dissertação (Mestrado em Sociologia) - Universidade Federal do Amazonas, Manaus, 2016.

GUIMARÃES, Paula Vitorino. O adolescente infrator em pauta: a presença de matérias sobre delitos envolvendo adolescentes na pauta diária do jornal online Campo Grande News. Revista Comunicação \& Mercado, Dourados/MS:UNIGRAM, v.4, n. 10, p. 118-129, dez. 2015. Disponível em: https://www.unigran.br/dourados/mercado/paginas/ arquivos/edicoes/10/10.pdf. Acesso em: 09 dez. 2019.

LA TAILLE, Yves de. Formação ética: do tédio ao respeito de si. Porto Alegre: Artmed, 2009.

MAGALHÃES, Vinicius Pinheiro de. Adolescentes infratores no Brasil: promotores da criminalidade ou vítimas dela? In: SEMINÁRIO DE PÓS-GRADUAÇÃO EM CIÊNCIAS SOCIAIS, 5., 2015, Cachoeira, BA. Anais [...]. Cachoreira, BA: Universidade Federal do Recôncavo Baiano, 2015. Disponível em: https://www3.ufrb.edu.br/sppgcs2015/

trabalhos-aprovados. Acesso em: 06 jun. 2019. Tema: Tradição e Modernidade: identidades, desigualdades e desenvolvimentos.

MINAYO, Maria Cecília de S. O desafio do conhecimento: pesquisa qualitativa em saúde. São Paulo: Hucitec, 2008.

ROSA, Miriam Debieux. A clínica psicanalítica em face da dimensão sociopolítica do sofrimento. São Paulo: Escuta, 2016.

SAFI, Sofia de Souza Lima. Consumo, logo existo: o atravessamento da cultura consumista em jovens em cumprimento de medidas socioeducativas. 2013. Trabalho de Conclusão de Curso (Bacharelado em Psicologia) - Universidade Federal do Rio Grande do Sul, Porto Alegre, 2013. Disponível em: https://www.lume.ufrgs.br/handle/10183/108585 . Acesso em: 09 ago. 2018. 
SECRETARIA DE PLANEJAMENTO E ORÇAMENTO (SEPLAN/TO). Perfil Socioeconômico dos Municípios. Secretaria de Governo, 2017. Disponível em:

https://central3.to.gov.br/arquivo/348373/ . Acesso em 17 fev.2020.

SOUZA, Jessé. A elite do atraso: da escravidão à Lava jato. Rio de Janeiro, Leya, 2017.

TEIXEIRA, Alessandra; SALLA, Fernando. De menores a adolescentes infratores: contribuições ao debate sobre a criminalidade juvenil. Revista Brasileira de Ciências Criminais, São Paulo, v. 126, p.267-290, dez. 2016.

Recebido em: 10/06/2019 Aprovado em: 12/02/2020

Universidade do Estado de Santa Catarina - UDESC Centro de Ciências Humanas e da Educação - FAED

Revista PerCursos

Volume 20 - Número 44 - Ano 2019 revistapercursos@gmail.com 